\title{
Research on Information Communication Carrier Network Frame of the Directly Affiliated Units of Energy Firms
}

\author{
Xiaoyun ZHANG ${ }^{1, a}$, Yan LIU ${ }^{2}$, Yinlin REN ${ }^{3}$, Wencui $\mathrm{LI}^{2}$ and Xiong $\mathrm{LI}^{2}$ \\ ${ }^{1}$ China Electric Power Equipment and Technology Co. Ltd., Zhengzhou Electric Power Design \\ Institute, Zhengzhou, 450000, China \\ ${ }^{2}$ Information \& Telecommunication Co. of State Grid Henan Electric Power Company, Zhengzhou, \\ 450052, China \\ ${ }^{3}$ Henan University of Technology, Zhengzhou, 450001, China \\ aemail: 25189385@qq.com
}

Keywords: Bandwidth Demand, Network Architecture Setup, Security Control

\begin{abstract}
At present, the information communication network of the directly affiliated units of energy firms has many problems, such as diverse access mode, weak operation and maintenance strength, and insufficient network bandwidth, leading to the consequences that the network construction standard is differentiated, the network operation management is backward, the cost of link is high, and the ability of communication resource sharing is poor, which has been unable to meet the requirements of the rapid development during the 12th Five-Year-Plan period. After analyzing the bandwidth demand, the total bandwidth demand of Henan province worked out to 1.7G. Then, the network architecture was studied on the principle of uniformity, economy, standard, security, compatibility and expandability. Finally, this paper proposed the measures of multi-level defense and horizontal isolation for security control to effectively guarantee the safe and stable aeration of the information communication carrier network of the directly affiliated units of energy firms.
\end{abstract}

\section{Introduction}

In the general environment of national informatization construction, the informatization construction of directly affiliated industrial units of energy enterprises is also developing rapidly. During the 12th five-year plan period, all the directly affiliated institutions put forward higher bandwidth demands from the current $2.5 \mathrm{G}$ to $10 \mathrm{G}$ in the construction of information communication network, making it urgent for each directly affiliated unit to meet the requirement of communication recourse. On the other hand, the information network of directly affiliated institutions needs to transform from decentralization to collectivization and integration based on energy firms "three intensification and five systems".

"Reducing exports, strengthening protection and monitoring" is the strategy now adopted by the state in Internet export, the moderate unification of which is the general trend. At present, many domestic and foreign enterprises have accomplished the work of unified Internet export, including China bank, China post, Huawei, Cisco and others. At the same time, the multi-channel business expansion and application of energy enterprises has increased the demand for the Internet, growing stressing on the centralized and effective risk control and management of Internet export. In addition, when carrying out communication operation business in the power system, there are problems like insufficient bandwidth capacity of backbone network and insufficient terminal access network, etc, causing the excessive rental costs and some market losses, to some extent, which restricts the scale operation of communication resources. In the view of the above problems, this paper studies the information and communication carrier network architecture of energy enterprises' direct units from three aspects: bandwidth demands, network architecture and security control. 


\section{Bandwidth Demand Analysis}

The increase in the bandwidth of the informatization construction of directly subordinate units is a rigid requirement for the rapid development of the direct affiliate itself. In the course of the 12th five-year plan , financial, direct industry and international business will account for $40 \%$ of the company's profit contribution, leading directly affiliated institutions to the backbone of energy enterprises' development, whose informatization should adapt to the overall level of the entire energy enterprise. With the rapid advancement of information construction, network resource is desperately in need.

According to the research results of information construction bandwidth demand during the 12th five-year plan period, it is estimated that the total bandwidth of the branches of the directly affiliated institutions is nearly 15G (including bandwidth of internal and external networks), whose average annual growth rate is about $50 \%$. The total bandwidth demand in Henan Province is $1.7 \mathrm{G}$.

The construction of information and communication bearing network of the directly subordinate units should fully inherit the achievements of the "11th five-year" information network, actively integrate the communication network transmission link resources and infrastructure at all levels of energy enterprises, adhere to the principle of "Comprehensive planning, simultaneous promotion, overall planning and step-by-step implementation", and develop communication networks based on local conditions to meet operational needs. The design of directly affiliated information communication bearing network follows the following principles:

Unity: Network architecture, network security and network management are all based on the "one whole". With collectivized operation and intensive management as the leading ideologies, integrated management, integrated construction, and integrated operation and maintenance are achieved.

Economy: Make full use of existing communication resource and equipment to establish a reasonable and efficient communication network.

Standard: Network planning complies with industry-recognized standards to ensure the exchange and interoperability between equipment and technologies, and facilitates the rapid deployment of new products and technologies to meet the rapid growth of the business.

Security: With a comprehensive network protection strategy, the network architecture must be able to meet/exceed the service level requirements of the business system to guarantee the security operation and failure recovery mechanism of the business.

Compatibility: It should be fully compatible with the existing power communication network system, closely connected, highly integrated, constituting an organic whole and reducing the complexity of system maintenance.

Scalability: On the premise of macroscopic development and forward-looking forecasts, network architecture should be easy to expand in terms of functions, capacity, and coverage, so as to adapt to the rapid development of business infrastructure requirements.

\section{Research on Bearing Network Architecture}

On the basis of the network bandwidth [1] requirement of the link between the local company and the provincial company, combined with the current situation of the communication network of the provincial company, the company's communication network resources are used to realize the data collection of the local company. The provincial company is the core node of the entire provincial network, also responsible for the data access to the next backbone network.

The deployment of $622 \mathrm{M}$ or $2.5 \mathrm{G}$ transmission equipment in the local company is to deal with the convergence and access of the relevant data of the city's nodes, constituting the data access points of the backbone network of the electric power enterprise's special network at the city level.

The terminal access network should take full advantage of the existing self-constructed fiber-optic private network. For the core and important nodes, it is considered to construct two optical fibers with different routes to implement service protection. As shown in Fig.1, configure the MSTP transmission equipment at the branch to connect the $155 \mathrm{M}$ upstream optical port to the 
155M optical port of the nearby power communication device.

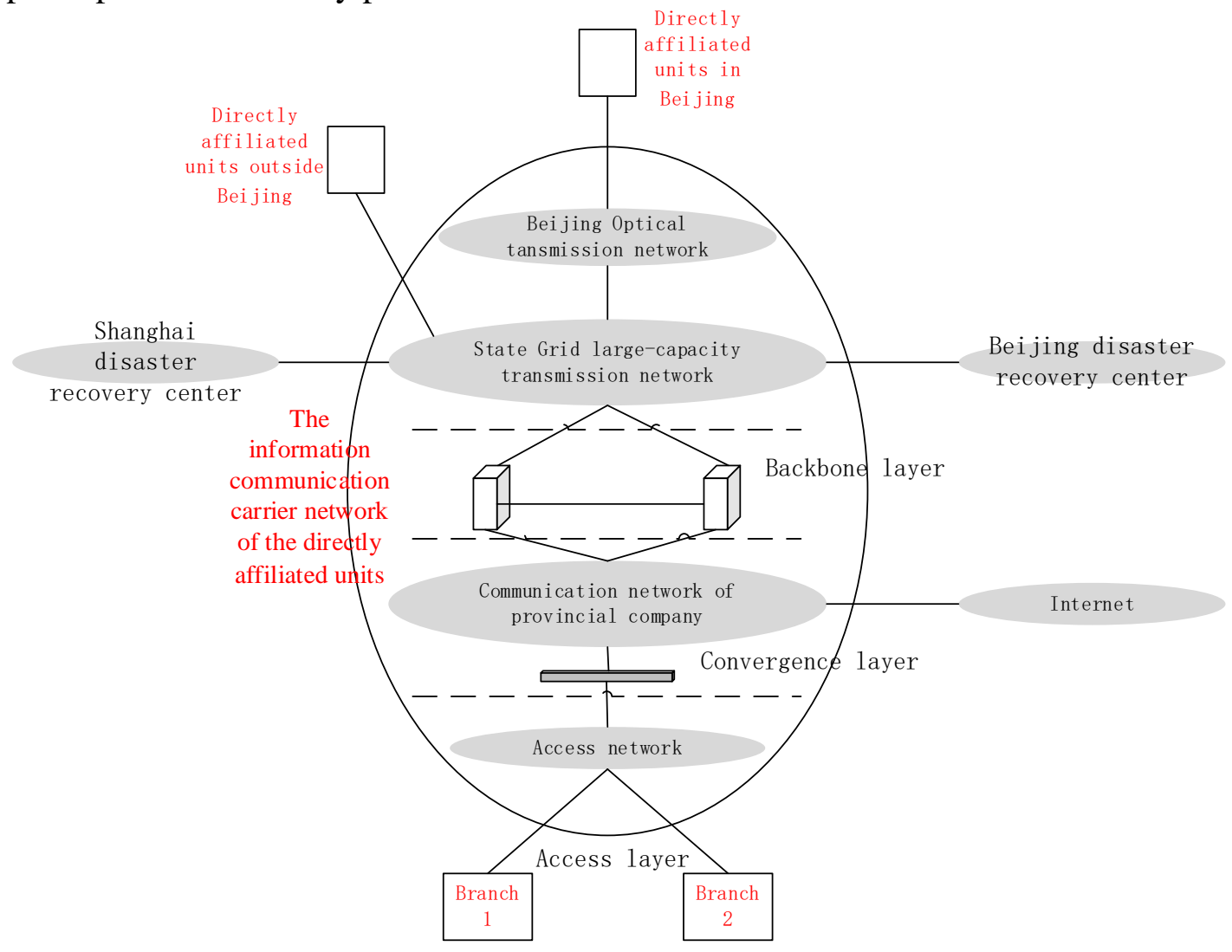

Fig. 1 The overall topology of the carrier bearer network

Business Flow Measurement Model. The information network of directly affiliated institutions can be divided into three levels, which respectively take charge of the network service traffic load from the directly affiliated unit headquarters to the company headquarters, from the subordinate branch structure to the directly affiliated unit headquarters, and from subordinate branches to the provincial Internet export. Therefore, the business flow model of the information communication carrier network of the directly affiliated unit is shown in Fig. 2.

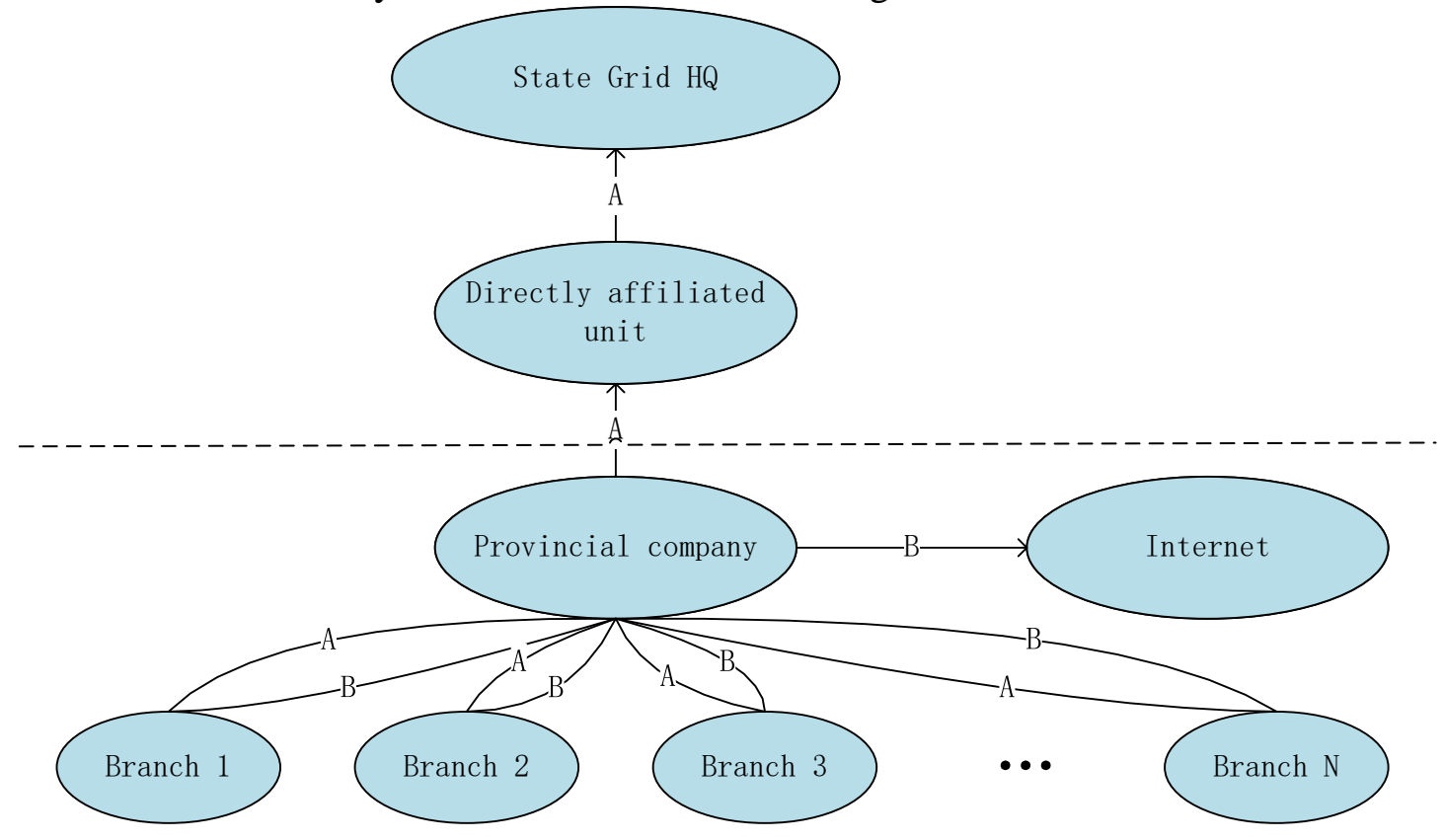

Fig. 2 Information network service traffic model of directly-owned units

Construction of Directly Affiliated Units. On the foundation of the original convergence point $\mathrm{A}, \mathrm{B}$ is added as the second convergence point to improve the network structure of each subordinate 
unit and enhance the security protection system. The direct subordinate unit is connected to A and B nodes via dual devices and dual links, as shown in FIG. 3, to realize the dynamic switching of the network double upper connection and improve the reliability of access to the network [2].

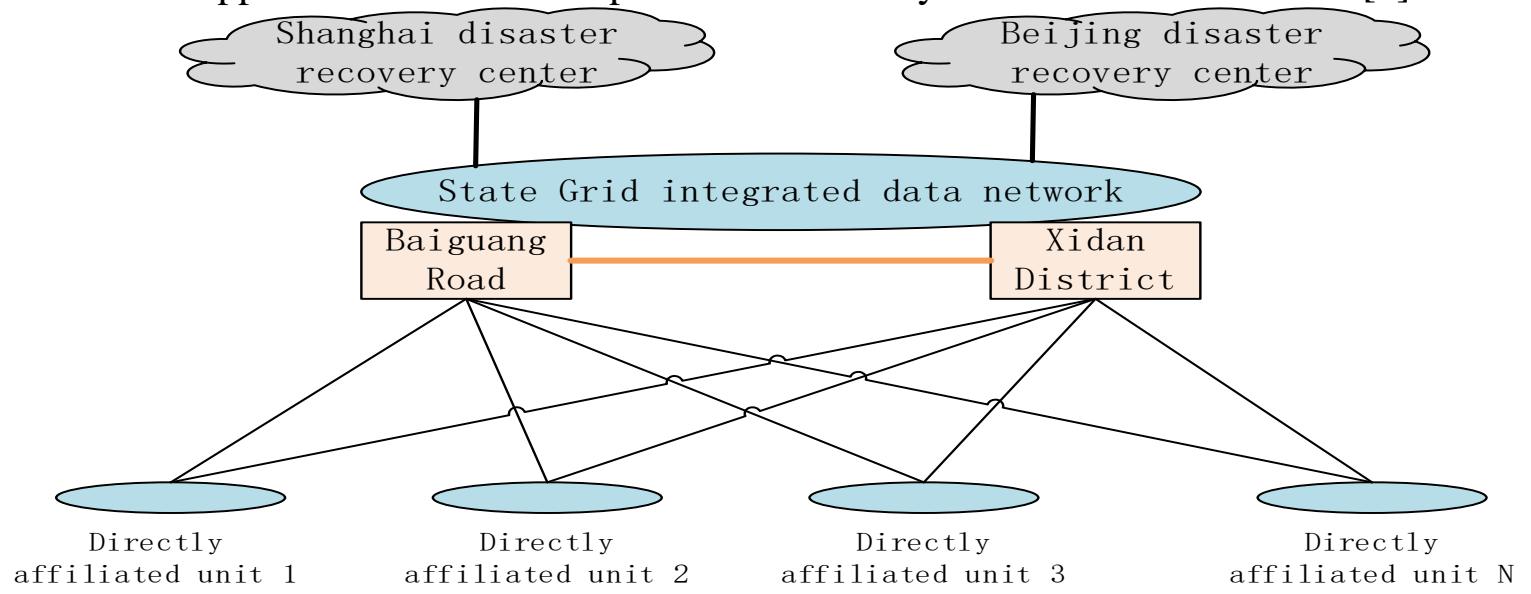

Fig.3 Planning topology of the access network of the directly affiliated unit

Branch Access Mode. Considering various factors such as office space, power resource coverage, business nature, capacity requirements, and staff size of branches of each directly-affiliated unit, secure, reliable, flexible and simple, and cost-effective access methods are adopted to make certain the safety and reliability of all branches [3].

On the principle of province concentration, city gather and close access, a multi-service integrated business information and communication network platform for the access of branches of directly subordinate entities is established. The intranet services of branches are aggregated through the private line from the various city companies' transmission network to the province, then through the large-capacity backbone optical transmission network to access the headquarters unit. By contrast, the external network services are gathered by individual line, and unified Internet exports are set up in each provincial company to achieve the external network access of branch structures [4] [5]. Fig. 4 shows the overall diagram.

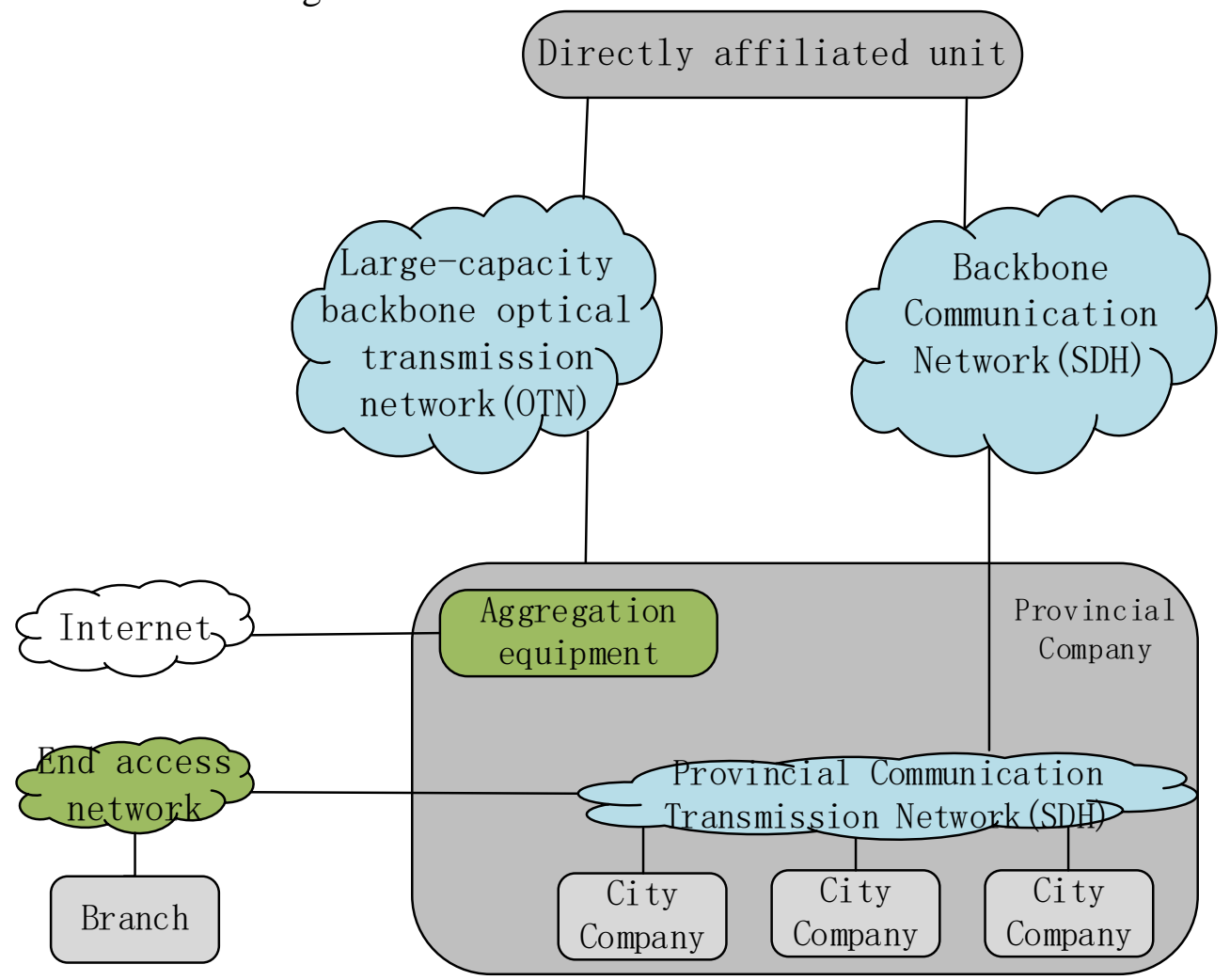

Fig.4 Schematic diagram of branch access 


\section{Security Management}

Make a good job of export security protection in light of the energy company's information security protection strategy [6] “distinguish domain, grade protection, multi-layer defense”. In order to strength the level of security management, all units' external information network is fully integrated into the ISS system [7] of the State Grid Corporation, monitoring the external information network of its directly affiliated unit without ISS probes deployed, transmitting the monitoring data to the company's headquarters and providing real-time Internet export security status and issues security alerts to the directly affiliated unit, as Fig.5 shows.

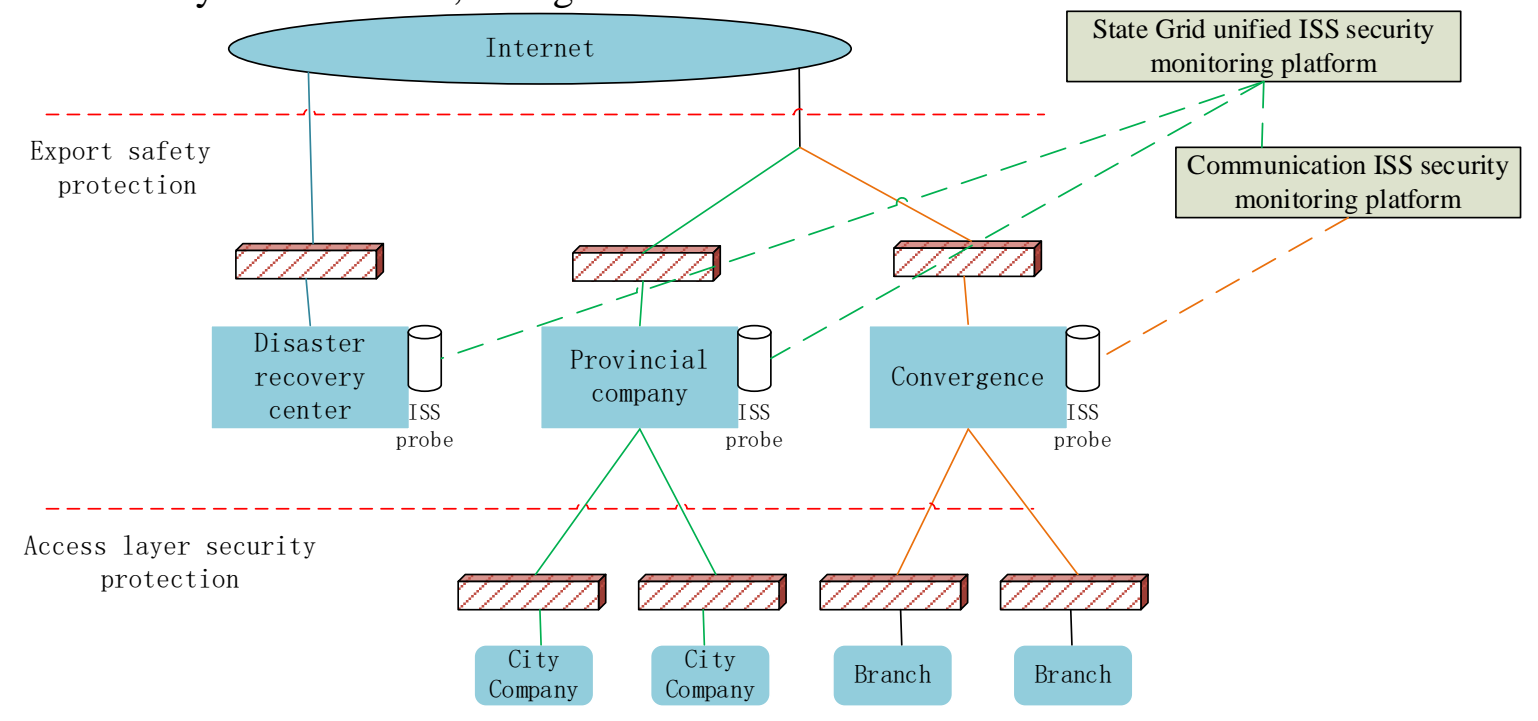

Fig.5 Safety monitoring structure diagram

(1) Multi-level defense: Monitor the security of exit points, convergence points, and boundary points of all units [8]. Strictly implement export firewalls, ISS, IP binding, intrusion prevention and other technical measures. Branches of companies and affiliates of cities and counties should use the original security monitoring equipment.

(2) Horizontal isolation: Horizontally segregate the information external network data traffic of provincial companies and directly-owned units. The Internet traffic of the directly affiliated companies and provincial companies will be split through network devices and monitored and reported separately [9] [10].

\section{Conclusion}

This paper discussed the issues of the bandwidth and capacity of the backbone network, the lack of access network at the end and so on. The information and communication bearer network architecture of the energy companies' direct units is studied from the aspects of bandwidth requirements, network architecture, and security management and control. A large-capacity, compatible, and expandable safety grid structure has been built to effectively guarantee the safe and stable operation of the information and communication bearer network of energy companies' directly subordinate units.

\section{References}

[1] WANG Wei, WANG Dan, YANG Yu-xuan et al. Research on Bandwidth Demand Forecasting Model for Electric Power Communication Network Traffic[J]. Electric Power Information and Communication Technology. 2015,(12): 119-124.

[2] Upama Vyas, Shashi Prakash. An improved scheduled traffic model utilizing bandwidth splitting in elastic optical networks[J]. Optical Fiber Technology. 2016:153-162. QUAN Nan, LEI Yu-Qing, HUANG Bi-Yao et al. Research on Architecture of Terminal Communication Access 
Network in Smart Grid[J]. Telecommunications for Electric Power System. 2012,(01):74-77.

[3] QUAN Nan, LEI Yu-Qing, HUANG Bi-Yao et al. Research on Architecture of Terminal Communication Access Network in Smart Grid[J]. Telecommunications for Electric Power System. 2012,(01):74-77.

[4] HUANG Xin, LI Qin, YANG Gui, et al. Network architecture design of smart substation based on software defined network [J]. Journal of Computer Applications. 2017, 9:2512-2517.

[5] BAI Long,Evolution of the Core Network Infrastructure in the Future[J]. Computer \& Telecommunication. 2016,12:51-52.

[6] CHEN Jie, LIU Jian-wei, WANG Meng-meng. Security Substrate Based Security Management and Control Mechanism of Reconfigurable Network[J]. Telecommunication Scince. 2014,7:19-25.

[7] Hartman S, Wasserman M, Zhang D. Security Requirement in the Software Defined Networking Model. IETF Draft(drafthartman-sdnsec-requirements),2013.

[8] Day J, Patterns in Network Architecture: A Return to Fundamentals, Edition I. Prentice Hall,2007.

[9] Jian Gang Tang,Shi Jun Zhang,Ji Jiang. Research on Network Security Issues and Security Model[J]. Applied Mechanics and Materials,2014,3009(519).

[10] Yan Bi. The Study on Network Security Strategy Based on Security Evaluation[J]. Applied Mechanics and Materials,2014,2802(443). 